\title{
Retrospective Study of Variations in Anterior Communicating Artery in Human Cadaveric Brains in Western Uttar Pradesh Region
}

Alok TRIPATHI a, Hina KAUSAR ${ }^{a}$, Ajay Kumar PATEL ${ }^{b}$, Shobhit RAIZADAYa, Shilpi JAINa, Satyam KHARE

aDepartment of Anatomy, Subharti Medical College, Swami Vivekanand Subharti University, Meerut, UP, India

bDepartment of Anatomy, All India Institute of Medical Sciences (AIIMS), Jharkhand, India

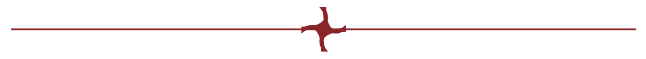

\begin{abstract}
Background: Anterior communicating artery connects the two anterior cerebral arteries across the commencement of the longitudinal fissure. Anterior communicating artery is an important artery to form the circle of Willis. The present study was conducted to know the variations of anterior communicating artery, including number, diameter, length, course and direction of placement. Knowledge of the variations of anterior communicating artery is important for radiologists, neurosurgeons and anatomists.

Materials and methods: This was a retrospective study with a duration of more than eight years, which was conducted on 100 adult embalmed human cadaveric brains conducted in the Department of Anatomy, Subharti Medical College, Swami Vivekanand Subharti University, Meerut, Uttar Pradesh, India. After removal of the brain from cadavers used in routine educational dissection for MBBS students, the anterior communicating artery was dissected and cleaned, then measurements were taken and digitally photographed.

Results: Among the 100 adult brains, the anterior communicating artery was absent in $3 \%$ of specimens. The course was oblique in $56 \%$ of specimens and horizontally placed in the remaining $44 \%$. No duplication or triplication was seen. The mean length was $2.80 \mathrm{~mm}$ and mean diameter $1.11 \mathrm{~mm}$.

Conclusion: From the present study we conclude that the variations of anterior communicating artery are common. The anterior communicating artery was absent in 3\% of specimens. Oblique and horizontal patterns were also seen. There was no duplication or triplication. Knowledge about the wide range of variations of this artery is important for neurosurgeons, radiologists and anatomists.
\end{abstract}

Keywords: ACoM anterior communicating artery, ACA anterior cerebral artery.

\footnotetext{
Address for correspondence:

Dr. Ajay Kumar Patel, Assistant Professor

Department of Anatomy, All India Institute of Medical Sciences (AIIMS), Deoghar, Jharkhand-814142, India

Tel.: +918860342412

Email: drajaykumar2008@gmail.com
}

Article received on the $6^{\text {th }}$ of July 2021 and accepted for publication on the $10 t^{\text {th }}$ of September 2021 


\section{INTRODUCTION}

1 nterior communicating artery connects the two anterior cerebral arteries across the commencement of the longitudinal fissure. It is an important artery in the formation of the circle of Willis. Aneurysm formation is a common finding found in the anterior communicating artery; these aneurysms can produce a variety of symptoms, including endocrine dysfunction and sometimes localized frontal headache. Both anatomical structure and physiological functions of the brain are complex but essential to sustain life. Starting from planning and initiation, voluntary movements, behaviour, memory, sensory and motor functions, hearing and vision, regulation of all visceral functions are directly or indirectly controlled by the brain. Despite intensive studies, the brain remains the most unexplored organ of the human body. Its anatomical localization and complex structures are probably contributory factors. The brain receives blood from two sources: the internal carotid artery and the vertebral artery. The internal carotid artery begins in the neck, where the common carotid artery bifurcates; as one of the terminal branches of the common carotid artery at the level of the upper border of the thyroid cartilage, it courses through the neck within the carotid sheath and then enters the skull into the petrous part of the temporal bone through the carotid canal. The internal carotid artery then runs forward through the cavernous sinus lying in the carotid groove on the side of the body of the sphenoid bone, and ends below the anterior perforated substance by dividing into two major cerebral arteries. The right and left vertebral arteries come together and join each other at the level of pons on the vertebral surface of the brain stem to form a midline single basilar artery, which runs in the basilar sulcus of the brain stem. The basilar artery, which runs in the basilar sulcus of the brain stem, joins the blood supply from the internal carotids in an arterial ring at the base of the brain, known as the circle of Willis. The posterior cerebral arteries at this confluence as do also two small bridging arteries, the anterior and posterior communicating arteries. The anterior communicating artery joins the two anterior cerebral arteries and takes part in the formation of the anterior part of the circle of Willis. Conjoining the two major sources of blood supply through the circle of Willis presumably improves the chances of any region of the brain continuing to receive the blood even if one of the major arteries becomes occluded, as seen in the case of thrombosis of one anterior cerebral artery due to inflow of blood from contralateral anterior cerebral artery through the anterior communicating artery.

The anterior cerebral artery is the smaller terminal branch of the internal carotid artery. Surgical nomenclature divides the anterior cerebral artery into three parts: A-1 segment, A-2 segment and $\mathrm{A}-3$ segment. The anterior communicating artery is the landmark of A- 1 segment of the anterior cerebral artery. A-1 segment starts from the origin of the anterior cerebral artery from the internal carotid artery up to the anterior communicating artery. The anterior cerebral artery starts at the medial end of the lateral fissure and passes anteromedially above the optic nerve to the great longitudinal fissure, where it is connected by the anterior communicating artery to another anterior cerebral artery.

The anterior communicating artery shows many variations such as absent, duplication, triplication, etc. It gives numerous anteromedial central branches that supply the optic chiasma, lamina terminalis, hypothalamus, para olfactory areas, anterior column of the fornix and the cingulate gyrus. Anterior communicating artery aneurysms are the most frequently occurring intracranial aneurysms and their surgical treatment is a crucial life-saving approach. For neurosurgeons, the knowledge of variations of the anterior communicating artery is important. Given that variations of the anterior communicating artery are common and the artery is deeply placed in the brain, knowledge of these variations of the anterior communicating artery is important for radiologists and anatomists too. The anterior communicating artery is also an important part of the circle of Willis to maintain the blood flow to the major areas of the brain.

\section{Aims and objectives}

The present study aims to obtain knowledge about the variations of the anterior communicating artery, including number, diameter, length, course and direction of placement, which is important for radiologists, neurosurgeons and anatomists. Aneurysms of the anterior communica- 
ting artery are common and require microsurgery as a life-saving treatment. At the same time, the artery is deeply placed into the brain and has lots of variations, so their knowledge is very important not only for anatomists and radiologists but also for neurosurgeons.

\section{MATERIALS AND METHODS}

$\mathrm{O}$ ur retrospective study with a duration of more than eight years (January 2013 to April 2021) was conducted on 100 adult embalmed human cadaveric brains in the Department of Anatomy, Subharti Medical College, Swami Vivekanand Subharti university, Meerut, Uttar Pradesh, India. After removal of the brain from cadavers for routine teaching of educational dissection among undergraduate students, the anterior communicating artery was dissected and cleaned, and measurements were taken with digital Vernier callipers and then digitally photographed. The external diameters were measured at its both ends and at midpoint, and finally the average diameter at the three points was obtained. Any anterior communicating artery with a diameter less than $1 \mathrm{~mm}$ has been described as hypoplastic by various authors, and this definition was accepted in the present study. Variations in the diameter, length, absence, number (duplication, triplication) placement (oblique or horizontally placed) were noted.

\section{Statistical analysis}

Lengths and diameters were calculated as mean \pm standard deviation. Incidences of variations were calculated as percentage. Quantitative parameters were compared by independent t-test. A p-value less than 0.05 was considered to be significant. All statistical analysis were carried out through statistical software SPSS version 25.0. $\square$

\section{RESULTS}

A mong the 100 explored brains, the anterior communicating artery were absent in $3 \%$ of specimens (Table 1, Figure 1). The course of anterior communicating artery was oblique in 56\% of specimens and horizontally placed in the remaining 44\% (Table 2, Figures 2 and 3). The anterior cerebral artery had a mean length of $2.80 \mathrm{~mm}$ (range $1.5 \mathrm{~mm}$ to $5.9 \mathrm{~mm}$ ) and a mean diameter of $1.11 \mathrm{~mm}$ (range $.59 \mathrm{~mm}$ to $2.1 \mathrm{~mm}$ ).

\begin{tabular}{|l|l|}
\hline Variations & Percentage of occurrence \\
\hline Absent & 3 \\
\hline Duplication & 0 \\
\hline Triplication & 0 \\
\hline
\end{tabular}

TA B LE 1. Variations in number of anterior communicating artery

\begin{tabular}{|l|l|}
\hline Variations & Percentage of occurrence \\
\hline Oblique & 56 \\
\hline Horizontal & 44 \\
\hline
\end{tabular}

TAB LE 2. Variations in the course of anterior communicating artery

\begin{tabular}{|l|l|}
\hline Variations & Percentage of occurrence \\
\hline Hypoplastic & 6 \\
\hline Plexiform & 0 \\
\hline Fusion & 2 \\
\hline Dimple & 0 \\
\hline
\end{tabular}

TABLE 3. Variations in the form of anterior communicating artery

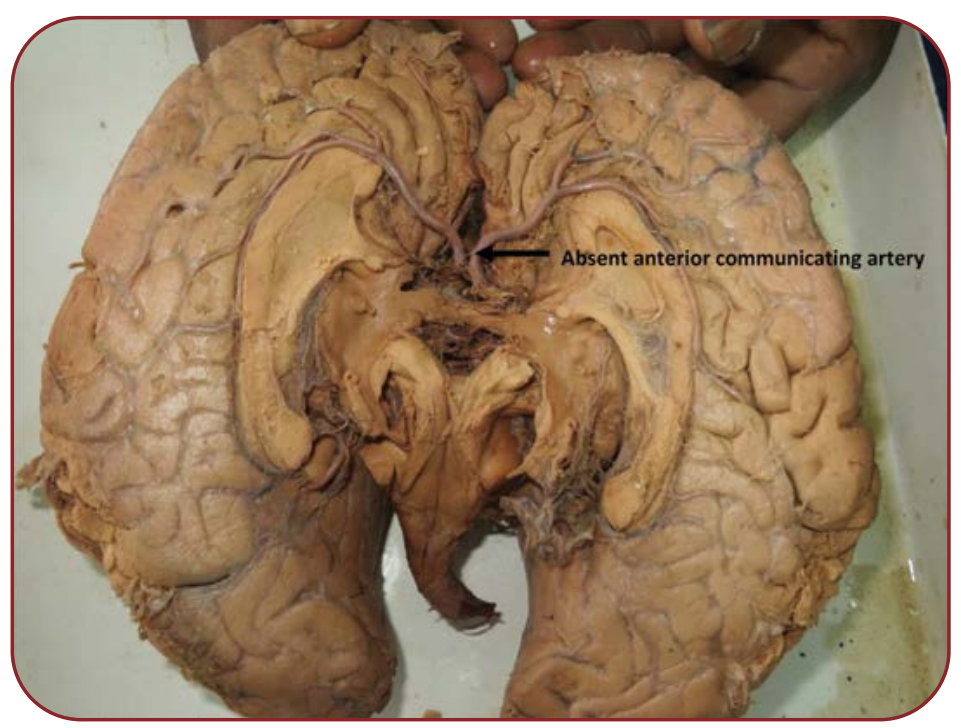

FIGURE 1. Absent anterior communicating artery

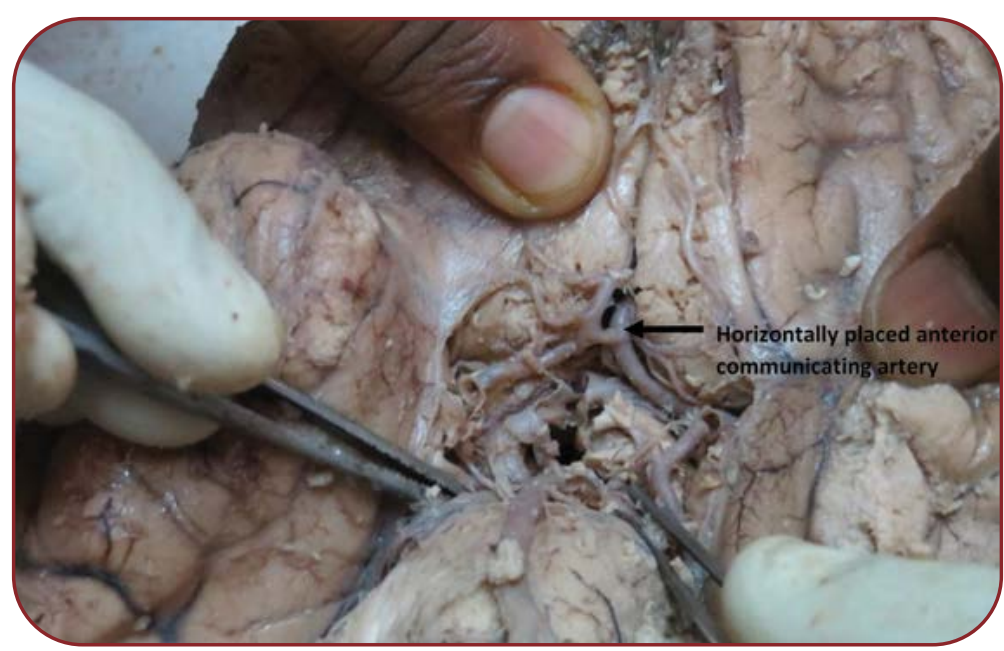

FIGURE 2. Horizontally placed anterior communicating artery 


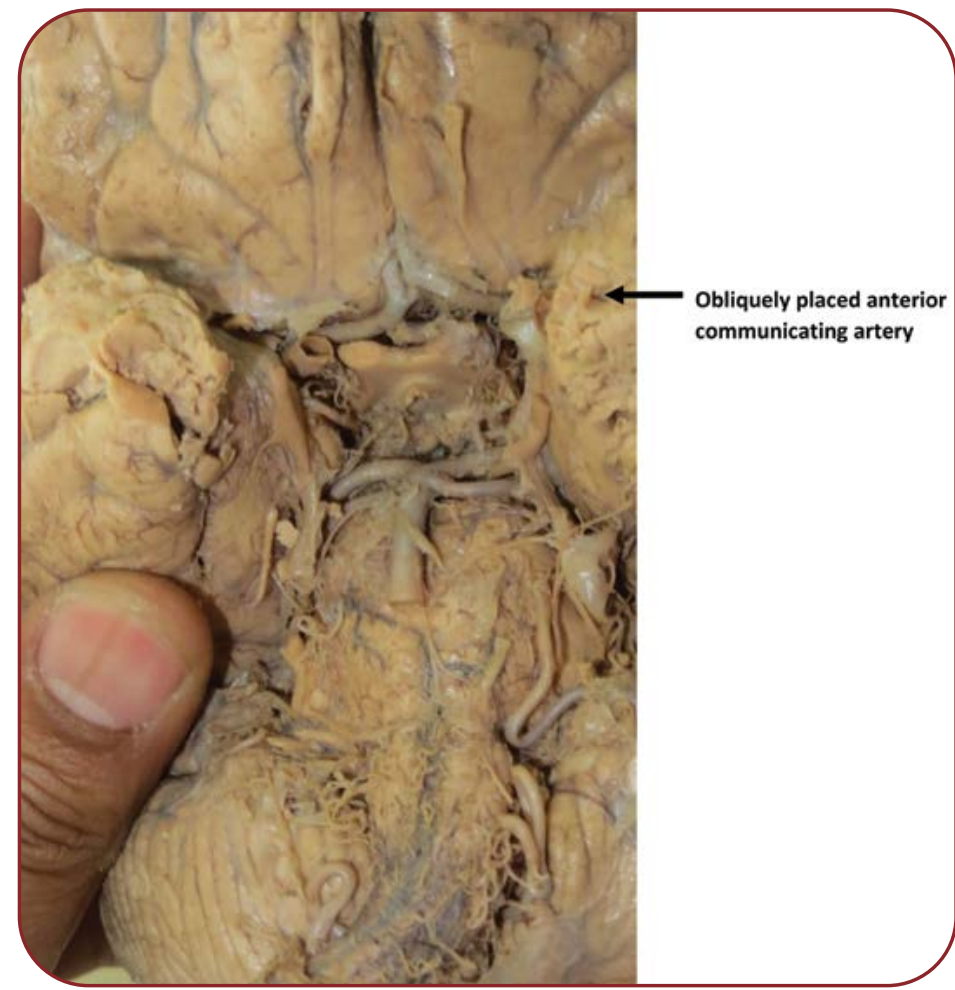

FIGURE 3. Obliquely placed anterior communicating artery

The hypoplastic anterior communicating artery was found in $6 \%$ of specimens, in which the diameter was less than $1 \mathrm{~mm}$, and was said to be hypoplastic (Table 3 ).

\section{DISCUSSION}

The anterior communicating artery is an important artery of the brain, which helps in the formation of circle of Willis in the anterior part and connects the two anterior cerebral arteries and completes the circle of Willis anteriorly. Posteriorly, the circle of Willis is completed by the posterior communicating artery by connecting the vertebral arterial system with the carotid system on either side. Some researchers believed the circle of Willis was complete even if the normal anterior communicating artery was absent and the anterior cerebral arteries were directly joined with each other. Such a circle of Willis should be considered anatomically incomplete but physiologically complete.

In the present study, the anterior communicating artery was absent in $3 \%$ of specimens. Fawcett and Blatchford (9), Blackburn (10), von Mitterwallner (11), Vare and Bansal (12), Jain (13) and Kanchan Kapoor (14) found the same variations of anterior communicating artery but less than that observed by us. Poorwa et al (15) have described the same variation but with a higher frequency than that found by us (Table 4).

Previous studies (7-15) reported duplication of anterior communicating artery, which was not found in our study at all.

Triplication of anterior communicating artery was not observed in our study, with the incidence of this variation being similar to that reported by Windle (7), Stopford (8), Fawcett and Blatchford (9), and von Mitterwallner (11), but it was found by other authors in their studies (12-15).

In the present study, the persistence of plexiform pattern of anterior communicating artery

\begin{tabular}{|l|l|l|l|l|l|l|}
\hline Author & $\begin{array}{l}\text { Brain } \\
\text { examined }\end{array}$ & Absent & Duplication & Triplication & Fusion & Plexiform \\
\hline Windle (7) & 200 & - & $11 \%$ & - & $3 \%$ & 0.55 \\
\hline Stopford (8) & 150 & - & $10 \%$ & - & $3.33 \%$ & $1.33 \%$ \\
\hline $\begin{array}{l}\text { Fawcett and Blatchford } \\
\text { (9) }\end{array}$ & 700 & $0.14 \%$ & $7.28 \%$ & - & - & $0.42 \%$ \\
\hline Blackburn (10) & 220 & $0.90 \%$ & $6.36 \%$ & - & - & - \\
\hline von Mitterwallner (11) & 360 & $0.2 \%$ & $20.55 \%$ & - & $1.66 \%$ & $1.33 \%$ \\
\hline Vare and Bansal (12) & 175 & $1.14 \%$ & $2.85 \%$ & $2.28 \%$ & - & - \\
\hline P. N. Jain (13) & 144 & $0.69 \%$ & $19 \%$ & $0.69 \%$ & $0.69 \%$ & - \\
\hline Kanchan Kapoor (14) & 1000 & $1.8 \%$ & $10 \%$ & $1.2 \%$ & - & $0.4 \%$ \\
\hline $\begin{array}{l}\text { Poorwa Baburao et al } \\
\text { (15) }\end{array}$ & 100 & $8 \%$ & $10 \%$ & $1 \%$ & $3 \%$ & $3 \%$ \\
\hline Present study & 100 & $3 \%$ & $0 \%$ & $0 \%$ & $2 \%$ & $0 \%$ \\
\hline
\end{tabular}

TABLE 4. VComparison of the present study with past studies on the anterior communicating artery 
was absent, but this variation was observed by many previous studies $(7-9,11,14,15)$.

We found that the anterior communicating artery had a mean length of $2.80 \mathrm{~mm}$ (range $1.5-5.9 \mathrm{~mm}$ ) and a mean diameter of $1.11 \mathrm{~mm}$ (range .59-2.1 mm).

Further research on anterior communicating artery can be done by including radiological and surgical findings too. Radiological and neurosurgical variations, along with morphometric anatomical analysis can be added in new studies of this important artery. In the future, we could compare the anatomical, surgical and radiological variations of the anterior communicating artery to get widespread results regarding these variations and enhance the knowledge about them.

\section{CONCLUSION}

n the present study we found that the anterior communicating artery had frequent variations and was absent in $3 \%$ of all explored specimens. The anterior communicating artery had an average length of $2.80 \mathrm{~mm}$ and an average diameter of $1.11 \mathrm{~mm}$, with a wide range of variation.
Oblique pattern was seen in $56 \%$ of specimens and horizontally placed anterior communicating artery in the remaining 44\%. In the present study, duplication and triplication were absent. The knowledge about the wide range of variations of the anterior communicating artery is very important for neurosurgeons, radiologists and anatomists because these variations are commonly encountered during neurosurgery of the anterior communicating artery aneurysms. The anterior communicating artery supplies many important structures of the brain and has a wide range of variations such as absence, duplication, triplication, hypoplastic, oblique or horizontal placement, lengths and diameters, which should be well known by neurosurgeons, radiologists and anatomists. The anterior communicating artery is part of the circle of Willis and helps to maintain the blood flow in the brain if one anterior cerebral artery is blocked due to any pathology. The knowledge about variations of anterior communicating artery is important in both brain surgery and radiology.

Conflicts of interest: none declared.

Financial support: none declared.

\section{R}

1. Susan Standring. Gray's Anatomy, $40^{\text {th }}$ edition, Elsevier, Churchill Livingstone, 2008, pp 251-252.

2. Chummy's S. Sinnatamby, Last's Anatomy, $12^{\text {th }}$ edition, Elsevier, Churchill Livingstone, 2011, pp 271-272.

3. Romanes GJ. Cunningham's Manual of Practice Anatomy. The Cranial Cavity, $15^{\text {th }}$ Edition, Vol. 3, Oxford Medical Publication, 2010, pp 43-44.

4. Bradley W, Daroff RB, Gerald M, et al. Neurology in clinical practices, $5^{\text {th }}$ edition, Vol. 2, Butterworth Heinmann, Elsevier, USA, 2008, pp 1243-1244.

5. Padget DH. The Circle of Willis, its embryology and anatomy, intracranial arterial aneurysms, Chapter 3, Comstock Publishing, New York, 1948:69-70.

6. Alper BJ, Berry RJ, Paddison RM. Anatomical studies of circle of Willis in normal brain.

Arch Neurology Psychiatry 1959;81:409-418.

7. Windle B.C. Arteries forming the circle of Willis.

Journal of Anatomy and Physiology
1888;22:289-293.

8. Stopford JSB; Arteries of the pons and medulla. Journal of Anatomy and Physiology 1916;50:131-64.

9. Fawcett and Blachford. The circle of Willis. Journal of Anatomy and Physiology 1905:40;63-70.

10. Blackburn. Anomalies of the Encephalic arteries among the insane. Journal Comp Neurol And Psych 1907;17:493-517.

11. von Mitterwallner $F$.

Variationsstatistische Untersuchungen an den basalen Hirngefäßen. Acta Anat 1955;24:51-58.

12. Vare AM, Bansal PC. Arterial pattern at the base of the human brain. Journal of Anatomical Society of India 1970;19:71-79.

13 Jain PN, Kumar V, Thomas RJ, Longia GS. Anomalies of Human Cerebral Arterial Circle.

Journal of Anatomical Society of India1990;39:137:46.
14. Kapoor K, Singh B, Dewan I. Variations in the configuration of the circle of Willis. Anatomical Science International 2008;83:96-106.

15. Poorwa Baburao Kardile, et.al. Anatomical Variations of the Anterior Communicating Artery. Journal of Clinical and Diagnostic Research 2013;7912:2661-2664.

16. Berk ME. Anomalies of the circle of Willis.

British Journal of Anatomy 1961;34:221-26.

17. De Oliveira JG, Mesnil de Rochemont $\mathbf{R}$, Beck J, et al. A rare anomaly of the anterior communicating artery complex hidden by a large broad neck aneurysm and disclosed by three-dimensional rotational angiography. Acta Neuro Chir (Wien) 2008;150:279-284.

18. Winn R, Youmans H. Neurological surgery, Vol 2, $5^{\text {th }}$ edition, Saunders, 1973, pp 1923-1947.

19. Henry Hollinshead. Head and Neck. In: Anatomy for Surgeons, Vol 1, $2^{\text {nd }}$ edition, 1968, pp 42-46, 57-60. 